\title{
Deformation behavior of AZ61 magnesium alloy systematically rolled and annealed at $450{ }^{\circ} \mathrm{C}$
}

\author{
B. Sułkowski*, P. Pałka \\ Department of Non-Ferrous Metals Engineering, Faculty of Non-Ferrous Metals, \\ AGH University of Science and Technology, 30 Mickiewicza Av., 30-059 Krakow, Poland
}

Received 13 April 2015, received in revised form 5 May 2015, accepted 7 July 2015

\begin{abstract}
Magnesium alloy AZ61 was processed by several thermomechanical routes consisting of hot-rolling at a high strain rate $\dot{\varepsilon}=1.6 \mathrm{~s}^{-1}$ and intermediate annealing. The total reduction of thickness was $83 \%$ after three routes. Intermediate annealing between routes was necessary to avoid sample fracture and to enhance the ductility. Texture investigations revealed that the basal type texture after deformation changed during a short time of annealing and the $\{11 \overline{2} 0\}<10 \overline{1} 0>$ component was strengthened. The structure investigations after rolling show the occurrence of a large fraction of twins inside the grains while after annealing no twins were left. It was found that the twins formed during rolling may support the texture transformation during annealing and enhance the ductility.
\end{abstract}

K e y w ord s: texture, twinning, magnesium alloys, recrystallization

\section{Introduction}

Magnesium alloys are widely used as structural materials because of their low density and high specific strength. Moreover, recently, magnesium alloys products have been found to be excellent candidates for hydrogen storage or even for medical applications especially if the material is processed by severe plastic deformation $[1,2]$. However, the plastic deformation of magnesium alloys is rather problematic due to the strong anisotropy of hexagonal structure [3]. During rolling or extrusion of magnesium alloys a strong basal texture evolves reducing ductility [4-8]. The ductility of magnesium alloys can be enhanced using weakening basal texture $[4,5]$. Velle [5] processed AZ61 magnesium alloy by the hot-rolling process with several intermediate annealing steps to achieve a large reduction in thickness. Due to the dynamic recrystallization during the process, the basal texture was reduced, increasing ductility. Zhang et al. [7] have investigated the formability of AZ31B alloy during the repeated unidirectional bending (RUB) process and annealing. Intermediate annealing of sheets during RUB processing leads to a weakening of the (0002) texture and enhancing the formability of AZ31B. Chino et al. [8] processed AZ31B by rolling in two different routes. Route A was special cross-rolling where each rolling direction changed at 90 degrees and route $\mathrm{B}$ was normal rolling where the rolling direction was always the same (see [8]). The formability of sheets was improved and attributed to a reduction in the (0002) texture intensity by the change of the rolling direction. Huang et al. [9] found less favor of the formation of the basal texture during deformation of AZ61 by a differential speed rolling (DSR) process where the shear component of deformation was introduced. Zhu et al. [10] processed AM60 magnesium alloy by the high strain rate rolling (HSRR) process at ambient temperatures and observed that at very high strain rates $\left(\dot{\varepsilon} \geq 2.9 \mathrm{~s}^{-1}\right)$ massive twinning occurs. The twins were then consumed by a dynamic recrystallization process (DRX) weakening the basal texture. Similar results were obtained by Ma et al. [6] during hot extrusion of AZ61 alloy. EBSD analysis showed that the $\{10 \overline{1} 2\}<\overline{1} 011>$ twins produced in large numbers during the extrusion process are in a crystallographic relationship with the new grains formed during DRX.

In this paper, AZ61 magnesium alloy was processed by hot rolling at high strain rates with the idea to introduce twins followed by intermediate annealing to 
Table 1. Summary of the sample names and conditions of rolling and annealing

\begin{tabular}{cccc}
\hline & & \multicolumn{2}{c}{ Sample name under conditions } \\
\cline { 3 - 3 } Route & Thickness reduction & as-rolled & $\begin{array}{c}\text { annealing temp. } 450^{\circ} \mathrm{C} \\
\text { annealing time } 15 \text { min }\end{array}$ \\
& & & - \\
0 & 0 & initial sample & $2 \mathrm{~B}$ \\
2 & $50 \%$ & $1 \mathrm{~A}$ & $3 \mathrm{~B}$ \\
3 & $69 \%$ & $2 \mathrm{~A}$ & $3 \mathrm{~A}$ \\
\hline
\end{tabular}
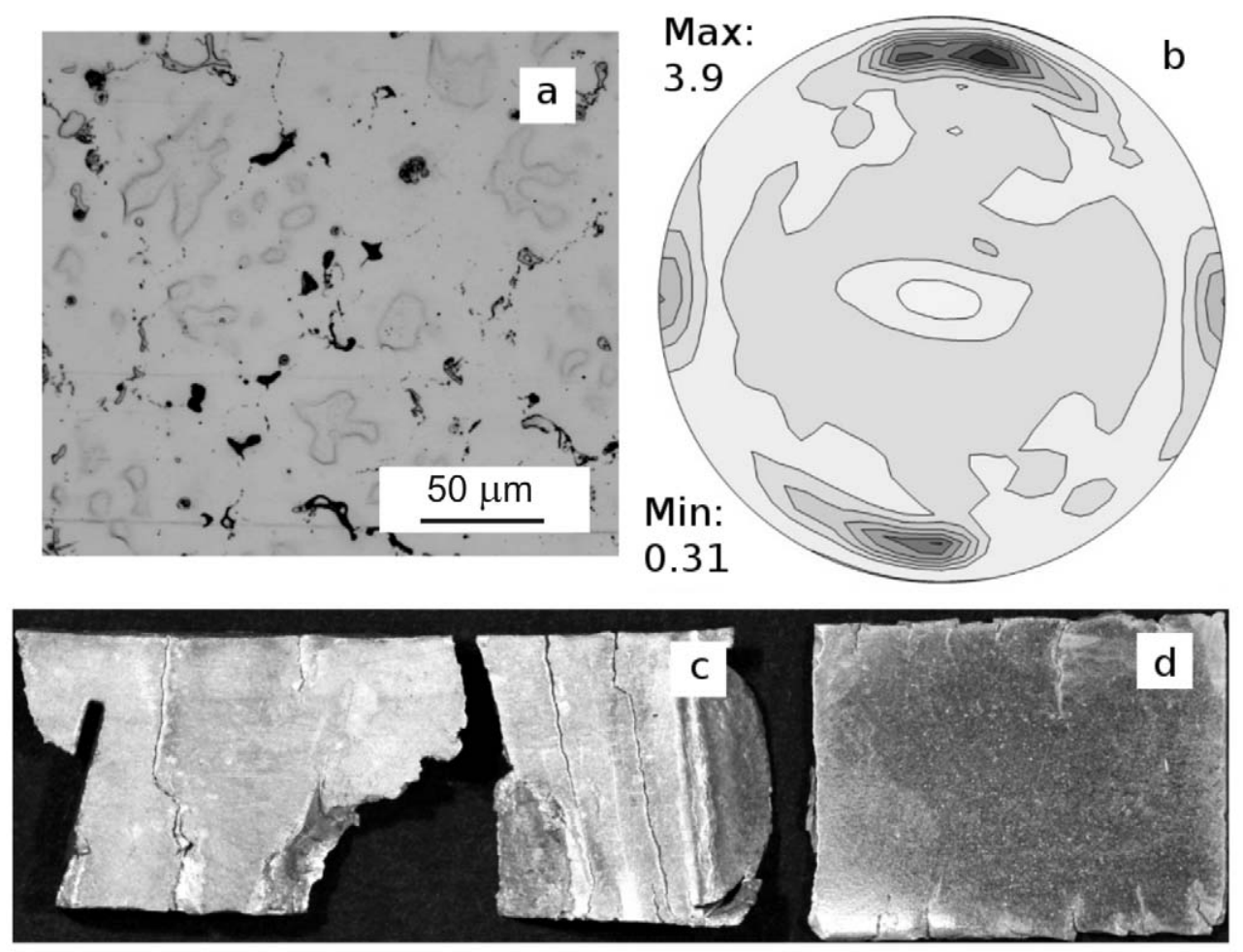

Fig. 1. a) Initial structure; b) (0002) pole figure after annealing at $450{ }^{\circ} \mathrm{C}$ and 1 hour before deformation; c) sample deformed to $69 \%$ of thickness reduction in two passes without annealing; d) 3A sample deformed to $83 \%$ total thickness reduction in three passes with intermediate annealings.

check whether there are significant texture changes which may have an effect on ductility.

\section{Experiments and results}

The AZ61 magnesium alloy studied in this paper was received in as-cast state by the provider. The main chemical components of the Mg-based alloy were as follows: $\mathrm{Al}$ (6 wt.\%), $\mathrm{Zn}(1 \mathrm{wt.} \%)$ and Mg-balanced. A $15 \mathrm{~mm} \times 15 \mathrm{~mm}$ rectangular-shaped and $50 \mathrm{~mm}$ long bar was prepared from as-cast billet. To obtain fine-grained material, the bar was preannealed in an electric furnace for $1 \mathrm{~h}$ at $450^{\circ} \mathrm{C}$. Immediately after annealing the bar was processed in sev- eral thermomechanical routes consisting of annealing for $15 \mathrm{~min}$ followed by rolling at $450{ }^{\circ} \mathrm{C}$ and a strain rate of $\dot{\varepsilon}=1.6 \mathrm{~s}^{-1}$ between not heated rolls. With each route, a $50 \%$ reduction of the current thickness was applied. There were three passes with a total reduction of the thickness of 50, 69 and $83 \%$, respectively. With the aim to study the effect of repetitive and alternating rolling and annealing on AZ61 properties after each route some piece of material was left for further investigations such as optical microscope observations, and texture measurements. Each piece of material was cut into two samples. The first sample was "as-rolled", and the second was annealed at $450^{\circ} \mathrm{C}$ for $15 \mathrm{~min}$. Table 1 summarizes the samples and conditions. 



Fig. 2. The microstructure after deformation to a) $69 \%$ and c) $83 \%$ of total thickness reduction; b) and d) after deformation followed by annealing for $15 \mathrm{~min}$.

From Table 1, the material under conditions 1B and $2 \mathrm{~B}$ was an input during rolling for routes 2 and 3 , respectively.

Figure 1 presents (a) the initial structure of AZ61, (b) annealed at $450{ }^{\circ} \mathrm{C}$ for $1 \mathrm{~h}$, (c) deformed to $69 \%$ of thickness reduction in two passes without annealing, (d) sample deformed to $83 \%$ (3A) total thickness reduction within three passes. The sample deformed to $69 \%$ of thickness reduction in two passes without annealing failures. However, small cracks near the edges of the sample $3 \mathrm{~A}$ can be observed.

To investigate the structure changes while rolling and annealing of AZ61 magnesium alloy the samples were prepared for optical observations. The preparations consist of grinding on carbon paper with gradation between 600 and 2000 and then polishing on Struers machine using diamond paste with the size of particles of $1 \mu \mathrm{m}$ followed by $0.25 \mu \mathrm{m}$. The grinding was carried out to achieve the middle part of each sample. To reveal the structure, the samples were etched by immersing them for $10-20 \mathrm{~s}$ in a $3 \%$ solution of nitric acid in glycol ethylene with the use of a stainless steel handler. Samples were investigated by an Olym- pus GX51 optical microscope. Figure 2 shows the microstructure of the samples.

In this study, during investigations using an optical microscope on the "as-rolled" samples, small recrystallization grains that form during the DRX process were rather rarely observed. This is rather in contradiction to [5] where a large number of small grains which were formed during DRX in rolled magnesium alloys at ambient temperatures were observed. Velle et al. [5] observed a structure consisting of large grains surrounded by small grains in deformed samples. Moreover, in these investigations, after deformation, a large number of twins were observed inside the grains which disappeared after annealing for $15 \mathrm{~min}$ at $450{ }^{\circ} \mathrm{C}$ while other authors did not observe twins in rolled AZ61. The reason for the discrepancies between literature and this study can be found in the strain rate applied. In the current investigations, the strain rate was $1.6 \mathrm{~s}^{-1}$ in each route while Velle applied $10^{-2} \mathrm{~s}^{-1}$. Twins can form in rolled magnesium alloys even at ambient temperatures at high strain rates $\left(\dot{\varepsilon}>10^{-1} \mathrm{~s}^{-1}\right)[10,11]$. Usually, twinning is favored at low temperatures for fcc, bcc, and hcp metals 


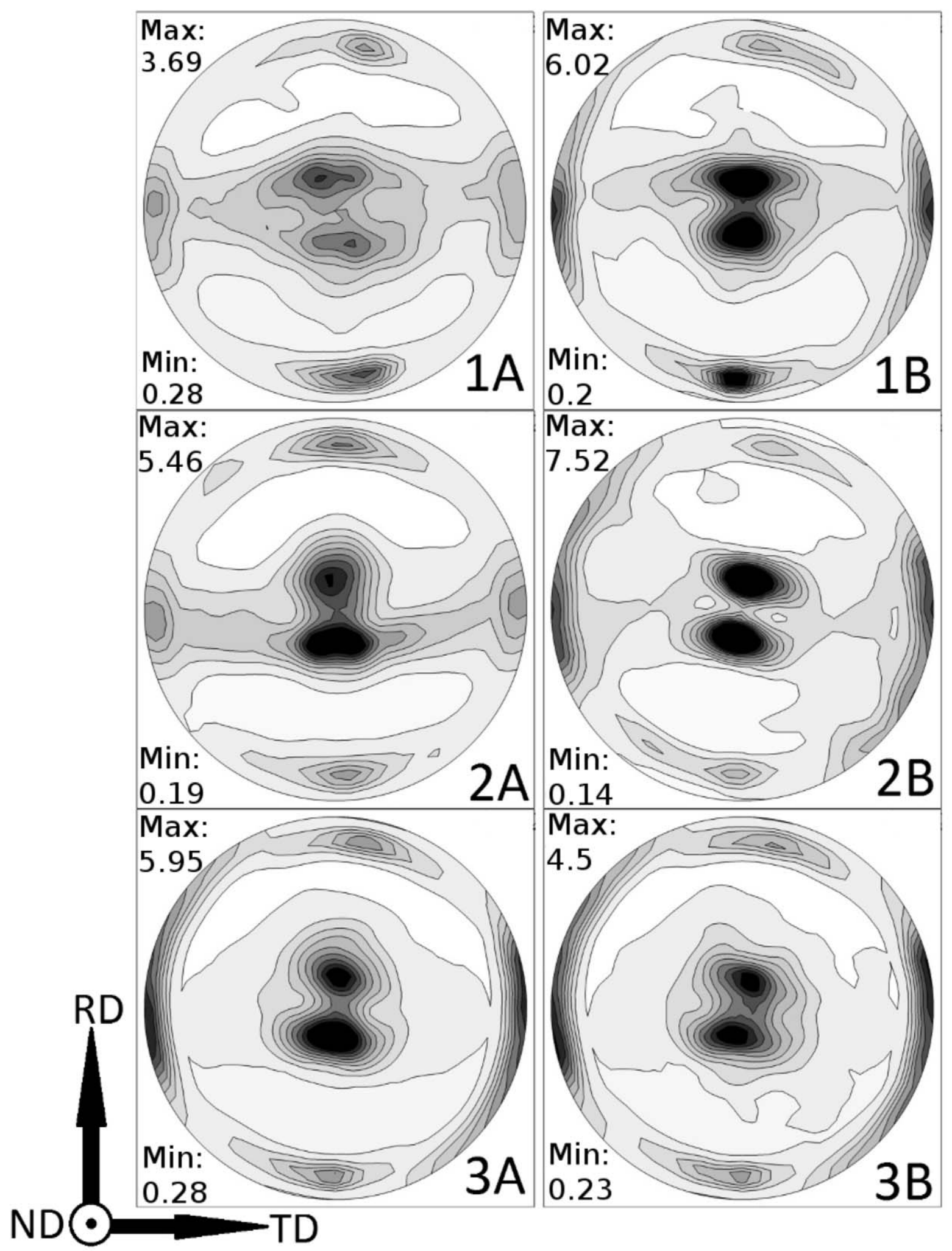

Fig. 3. The (0002) pole figures for initial, deformed and annealed samples of AZ61 magnesium alloy.

but, on the other hand, twinning is more sensitive to the strain rate [12]. Zhu et al. [10] observed that profuse twinning occurs in rolled ZK60 at strain rates higher than $2.9 \mathrm{~s}^{-1}$ in samples heated to $300{ }^{\circ} \mathrm{C}$ and rolled between not heated rolls.

Crystallographic textures for all of the samples 
listed in Table 1 were measured using X-ray diffraction with the use of Bruker D8 Advance device with $\mathrm{Cu} \mathrm{K} \alpha$ radiation operating at $30 \mathrm{kV}$. For each sample, the (0001), $\{10 \overline{1} 0\},\{11 \overline{2} 0\}$ and $\{10 \overline{1} 1\}$ pole figures were measured with step size $5 \times 5$. Using MTEX application under MATLAB, the calculated pole figures were generated and corrected by the defocusation data.

The (0002) pole figures for an initial sample before deformation as well as for the deformed and annealed samples are shown in Fig. 3. The initial textures are composed of weak $\{11 \overline{2} 0\}<10 \overline{1} 0>$ and strong $\{10 \overline{1} 0\}<11 \overline{2} 0>$ main components. The texture after deformation but not annealed is a basal type texture, similar to that which is observed for rolled hexagonal metals with $c / a>1.633$. (0002) peak is split into two tilted toward rolling direction (RD). The mechanism why the peak along (0002) is split into two and tilted toward rolling direction is not known yet.

During annealing of deformed AZ61 samples, the texture changed. After $15 \mathrm{~min}$. of annealing at $450^{\circ} \mathrm{C}$ the intensity of the basal texture was smaller than for "as-rolled" samples and the peaks along (0002) were much more sharp. After recrystallization of AZ31 at $723 \mathrm{~K}$, the (0002) basal and $\{10 \overline{1} 0\}$ fibers components of the texture are retained while $\{11 \overline{2} 0\}$ fiber is strengthened [13]. However, in this study $\{11 \overline{2} 0\}<10 \overline{1} 0>$ component was strengthened during short time annealing. The strengthening of $\{11 \overline{2} 0\}<10 \overline{1} 0>$ was observed in long time annealing of hot-extruded AZ61 [4] where abnormal growth of grains with prismatic planes $\{11 \overline{2} 0\}$ parallel to the sheet plane and with $<10 \overline{1} 0>$ directions parallel to the extrusion direction (ED) was observed. The evolution of basal texture during hot rolling and annealing of AZ61 was changed in a cyclic way, and the twins which form during rolling may support the texture changes during static annealing, enhancing the ductility of magnesium alloys.

The twinning has an effect on the texture after annealing for $\mathrm{Mg}$ alloys. Ma et al. [6] observed a relation between the recrystallization directions and twinning in AZ61 and concluded that some grains satisfy the $\{10 \overline{1} 2\}<\overline{1} 011>$ twin orientation relationship. A large proportion of the strain energy is stored in twins, which can apparently provide a driving force for fast grain growth. This mechanism can be very similar to that described by Zou et al. [14].

\section{Conclusions}

- AZ61 was deformed by rolling to large thickness reduction at a high strain rate;
- after rolling the texture is of the basal type with [0001] split into two peaks toward RD;

- during intermediate annealing $\{11 \overline{2} 0\}<10 \overline{1} 0>$ component of texture is strengthened;

- twins which form during rolling may support the texture changes during static annealing;

- texture changes have an impact on enhancing the ductility of AZ61.

\section{Acknowledgements}

The project was performed within the activity (11.11. 180.653) of the Department of Materials Science and Non-Ferrous Metals Engineering at AGH-UST Krakow, Poland.

\section{References}

[1] Krystian, M., Zehetbauer, M. J., Kropik, H., Mingler, B., Krexner, G.: J. Alloy Comp., 509, 2011, p. 449. doi:10.1016/j.jallcom.2011.01.029

[2] Chen, Y., Xu, Z., Smith, C., Sankar, J.: Acta Biomater, 10, 2014, p. 4561. doi:10.1016/j.actbio.2014.07.005

[3] Kelly, W. E.: Technical Report: The Plastic Deformation of Magnesium. Michigan, University of Michigan 1967.

[4] Pérez-Prado, M. T., Ruano, O. A.: Scripta Mat., 48, 2003, p. 59. doi:10.1016/S1359-6462(02)00346-9

[5] Valle, J. A., Pérez-Prado, M. T., Ruano, O. A.: Mater Sci Eng. A, 355, 2003, p. 68. doi:10.1016/S0921-5093(03)00043-1

[6] Ma, Q., Li, B., Marin, E. B., Horstemeyer, S. J.: Scripta Mat., 65, 2011, p. 823. doi:10.1016/j.scriptamat.2011.07.046

[7] Zhang, H., Huang, G., Song, B., Zhang, L., Kong, D.: Trans Nonferrous Met Soc China, 21, 2011, p. 844. doi:10.1016/S1003-6326(11)60791-7

[8] Chino, Y., Lee, J. S., Sassa, K., Kamiya, A., Mabuchi, M.: Materials Letters, 60, 2006, p. 173. doi:10.1016/j.matlet.2005.08.012

[9] Huang, X., Suzuki, K., Saito, N.: Scripta Mat., 60, 2009, p. 651. doi:10.1016/j.scriptamat.2008.12.035

[10] Zhu, S. Q., Yan, H. G., Chen, J. H., Wu, Y. Z., Liu, J. Z., Tian, J.: Scripta Mat., 63, 2010, p. 985. doi:10.1016/j.scriptamat.2010.07.029

[11] Ma, Q., Li, B., Oppedal, A. L., Whittington, W. R., Horstemeyer, S. J., Marin, E. B., Wang, P. T., Horstemeyer, M. F.: Mater Sci Eng A, 559, 2013, p. 314. doi:10.1016/j.msea.2012.08.104

[12] Christian, J. W., Mahajan, S.: Prog Mater Sci., 39, 1995, p. 1. doi:10.1016/0079-6425(94)00007-7

[13] Wang, Y. N., Huang, J. C.: Mater Chem Phys, 8, 2003, p. 11. doi:10.1016/S0254-0584(03)00168-8

[14] Zou, J. X., Sinclair, C. W., Wagner, F.: In: Proceedings of the 8th International Conference on Magnesium Alloys and Their Applications. Ed.: Kainer, K. U. Weimar, DGM Germany 2009, p. 233. 